\title{
Evidence for ancient genetic subdivision among recently fragmented populations of the endangered shrub Grevillea caleyi (Proteaceae)
}

\author{
TM Llorens, DJ Ayre and RJ Whelan \\ Department of Biological Sciences, Institute for Conservation Biology, University of Wollongong NSW 2522, Australia
}

\begin{abstract}
The genetic effects of population fragmentation cannot be interpreted without understanding the underlying pattern of genetic variation resulting from historic population processes. We used AFLP markers to determine genetic structure and distribution of genetic diversity among populations of an endangered Australian shrub Grevillea caleyi (Proteaceae). Populations that occurred historically on four ridges have new been fragmented to varying degrees, producing some large, relatively pristine populations and very small populations consisting of fewer than 10 adult plants. We found marked population genetic structure (65.9\% of genetic variation was among populations) and a significant relationship between genetic and geographic distance $\left(r_{\mathrm{m}}=0.564, P=0.004\right)$. However, only $14 \%$ of overall genetic differentiation was attributable to variation
\end{abstract}

among ridges, compared with $52 \%$ among populations within ridges. Moreover, genetic diversity within samples of plants did not vary with either population size or degree of isolation. Thus, the present genetic structure of populations is probably almost entirely the product of historical events. Fine-scale structuring within populations prior to fragmentation may have been caused by limited seed and pollen dispersal, despite a complex suite of (mostly avian) pollinators, and a mixed mating system that allows a large amount of selfing. The combined effects of adult longevity and a soil-stored seed bank may have buffered the recently fragmented populations against the effects of dramatic reductions in numbers of adult plants.

Heredity (2004) 92, 519-526, advance online publication, 10 March 2004; doi:10.1038/sj.hdy.6800444

Keywords: habitat fragmentation; population isolation; population size; genetic diversity; genetic structure; AFLP

\section{Introduction}

Population genetic theory predicts that small, isolated populations should experience increased random genetic drift and inbreeding and reduced interpopulation gene flow (Wright, 1969; Barrett and Kohn, 1991). This may in turn result in a depletion of genetic diversity within populations, increased genetic divergence among populations, inbreeding depression and reduced fitness (Barrett and Kohn, 1991; Young et al, 1996), and may ultimately cause local extinctions (Frankham and Ralls, 1998). Consequently, in recent years much attention has been focused on the potentially deleterious genetic consequences of habitat fragmentation for plants. A growing body of empirical evidence provides support for some of these predictions (eg, Oostermeijer et al, 1995; Newman and Pilson, 1997; Morris et al, 2002), but many studies have failed to find the predicted consequences of habitat fragmentation (Montgomery et al, 2000), or have even found evidence to directly counter this theory (Foré et al, 1992).

The apparent lack of a uniform genetic response to habitat fragmentation may reflect the interaction of a complex set of factors that include breeding system,

Correspondence: RJ Whelan, Department of Biological Sciences, Institute for Conservation Biology, University of Wollongong NSW 2522, Australia. E-mail: rob@uow.edu.au

Received 17 September 2002; accepted 3 December 2003; published online 10 March 2004 pollination mechanism, seed dormancy, seed dispersal, geographic range and the genetic basis of inbreeding depression (Loveless and Hamrick, 1984; Husband and Schemske, 1996; Gibbs, 2001). In many cases, the apparent lack of a genetic response to habitat fragmentation may be primarily due to insufficient time having elapsed since fragmentation. This is particularly likely in studies involving long-lived species, as genetic impacts may not become apparent for many generations after a fragmentation event (Barrett and Kohn, 1991). In addition, many species have had a long history of natural population subdivision, due to natural habitat discontinuities or aspects of the species' biology. For these species, the genetic signatures of historical population processes may be so substantial that they obscure the effects of recent fragmentation. However, studying such species may provide insights into the potential long-term genetic consequences of recent habitat fragmentation.

Here, we investigate the genetic diversity and structure of populations of the endangered perennial shrub Grevillea caleyi R. Br. (Proteaceae). For this species, we attempt to assess the relative genetic impacts of recent, anthropogenically produced habitat fragmentation, and historical patterns of population subdivision. G. caleyi is naturally restricted to the laterite soils of four ridges within an area of approximately $8 \times 8 \mathrm{~km}$ in the northern suburbs of Sydney, Australia. Based on habitat characteristics, it is probable that G. caleyi historically consisted of four large populations, with one occurring on each ridge (Scott et al, 1995). However, following 
recent urbanisation in the area (mostly post-1900), an estimated $85 \%$ of the species' habitat has been lost. Each ridge now contains several $G$. caleyi populations that presumably represent the only remaining fragments of a single, much larger and essentially continuous, former population (Scott et al, 1995). As most of the few remaining patches of habitat that appear suitable for the species contain a G. caleyi population, it is likely that most of the $85 \%$ of lost habitat also contained G. caleyi. There are currently more than 20 known populations, all of which are smaller in size and more isolated than they would have been prior to the last century ( $T$ Auld, personal communication), but which have been affected by fragmentation to different degrees: populations now vary dramatically in size (from less than 10 to several thousand plants) and degree of isolation from the nearest population (from $300 \mathrm{~m}$ to $2.2 \mathrm{~km}$ ). Populations also differ to some extent in their fragmentation history, because although the majority of habitat losses occurred over 50 years ago, some significant losses were still occurring up to the 1970s (T Auld, personal communication).

We predicted that ancient restrictions in gene flow, due to limited pollinator movements and lack of seed dispersal, should have produced high levels of genetic differentiation both within and among ridges. Recent fragmentation may promote additional genetic differentiation within ridges if habitat changes reduce the abundance or foraging distances of avian pollinators, or if honeybees reduce outcrossing; however, this may be hard to detect if there was indeed pre-existing genetic structuring within ridges. It is unlikely that recent increases in population isolation would have affected genetic diversity, as the species probably has naturally low levels of gene flow, and the current degree of population isolation is confounded by historical isolation among ridges. However, we may be able to detect some effects of the recent fragmentation if it has caused reductions in genetic variation, as these reductions should be most apparent within the populations that are currently the smallest (Barrett and Kohn, 1991). We tested these predictions using a survey of genetic variation at 39 putative amplified fragment length polymorphism (AFLP) loci to partition genetic diversity within and among populations.

\section{Materials and methods}

\section{Biology}

G. caleyi occurs in open forest on lateritic soils. Plants are typically distributed in a series of discrete patches, grow to approximately $3 \mathrm{~m}$ tall and $4 \mathrm{~m}$ wide, and do not become reproductive until 2-5 years of age. They have large, red, toothbrush-shaped inflorescences that produce large quantities of nectar. Flowers are visited by a diverse suite of nectar-feeding birds (Scott et al, 1995), mainly several species of honeyeater (Family Meliphagidae) and the Silvereye (Zosterops lateralis). The introduced honeybee Apis mellifera is also a frequent flower visitor ( $\mathrm{T}$ Llorens, personal observation). The species is self-compatible, and readily sets seed both by autogamy and after visits by pollinators ( $\mathrm{T}$ Llorens, unpublished data).

Gene flow within populations should be facilitated by pollen movement via the highly mobile bird pollinators, which often forage extensively throughout a population ( $T$ Llorens, personal observation). However, most pollen-mediated gene flow may be very localised, even within continuous populations, because nectar-feeding birds may forage more within plants and within patches of plants than between them (Turner et al, 1982; T Llorens personal observation). Birds may transfer pollen between plants on different ridges, but the distances involved and the likelihood that birds perceive the inter-ridge valleys as barriers to movement suggest that levels of gene flow among ridges may have been historically low and that most gene flow historically occurred within ridges. European honeybees have been in this system since the early to mid-1800s, and have therefore been a potential disturbance while habitat losses were occurring. These introduced insects harvest $G$. caleyi nectar typically without contacting stigmas, they sometimes harvest pollen, and they typically make short-distance foraging movements (T Llorens unpublished data). The honeybee may therefore have had a recent impact on bird visits, the mating system and gene flow.

Fruits dehisce to release a single woody seed, which is large (15-20 mm long) and heavy (300-400 mg), and is dispersed by gravity alone. There is no apparent mechanism for secondary seed dispersal (Auld and Denham, 1999), so seed-mediated gene flow is expected to be very unlikely. Seeds enter and remain in a soilstored seed bank until fire stimulates mass germination. There is negligible germination between fires, and adult plants are killed by fire, so populations are typically even-aged. In the absence of fire, adult plants senesce rapidly at about 12-15 years of age (Scott et al, 1995). Therefore, the time elapsed since the most recent fire (= population 'age') determines, to some extent, plant abundance.

\section{Population sampling}

In 1997, we sampled eight populations of G. caleyi from four ridges (Figure 1). Estimates of population age at the time of sampling varied from 2 to more than 13 years (Table 1), and may have caused an artificially low census size in the three older populations (DF, NR and FW). Estimates of the age at which the previous generation was burned were available for five populations (Table 1; information from Scott et al, 1995). The two smallest populations (MR and LR) have had two fires in quick succession, which may have contributed to their current small size. No further information on fire history was available for the sites.

We collected one leaf/plant for each of 10 adult plants, with the exception of Myoora Rd, where we sampled the entire adult population of nine plants. All other populations were subsampled using a stratified random approach, where sampling reflected the pattern of distribution of plants within a population and covered the full geographic extent of each population. This approach was designed to maximise the amount of each population's genetic diversity sampled. Although a narrow strip of land within the known altitudinal range of G. caleyi connects Ridges 1 and 2 (Figure 1), the habitat characteristics across this area were such that we considered it unlikely that the G. caleyi populations from each ridge had been connected in the recent past. 


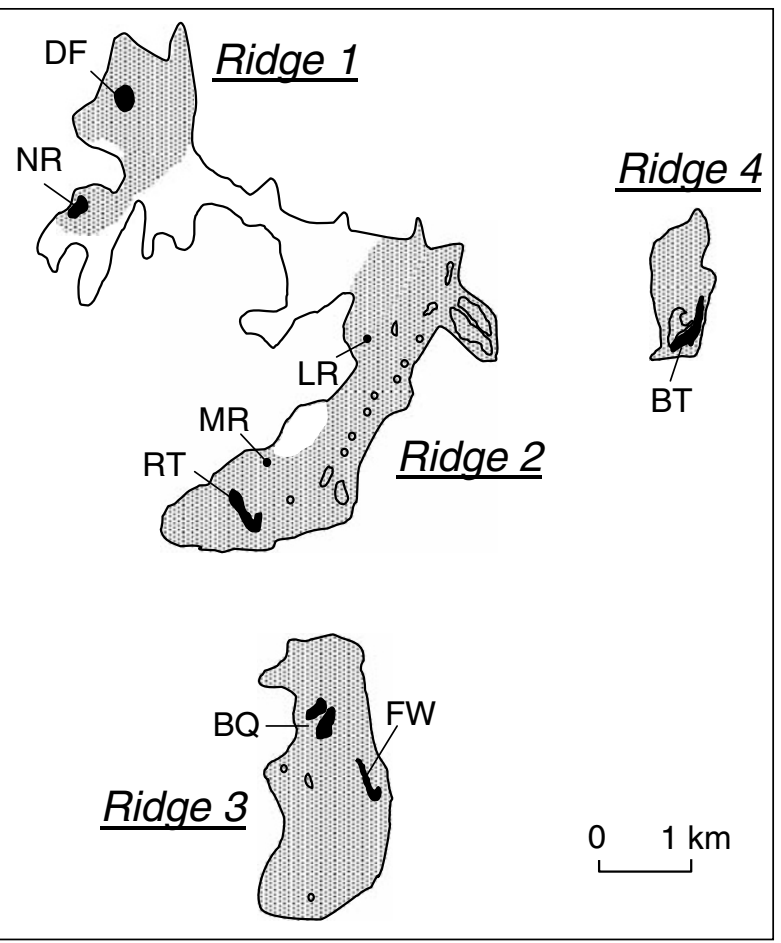

Figure 1 Map showing the location and approximate extent of all known natural $G$. caleyi populations on four ridges. The eight populations used in this study are shaded. Stippling indicates the distribution of G. caleyi habitat, and presumably of the species, prior to urbanisation.

Therefore, we considered these as separate ridges for the purposes of this study.

\section{DNA extraction}

For each leaf, we extracted genomic DNA from 15 to $20 \mathrm{mg}$ of fresh or frozen $\left(-20^{\circ} \mathrm{C}\right)$ tissue using a CTAB procedure slightly modified from Doyle and Doyle (1987), with $1 \% \mathrm{w} / \mathrm{v}$ polyvinylpyrrolidone (PVP MW 40000 ) added to the extraction buffer. We ground leaf tissue in liquid nitrogen before the addition of extraction buffer. Following extraction, we resuspended the DNA in $50 \mu \mathrm{l}$ TE buffer, and stored it at $-20^{\circ} \mathrm{C}$. We estimated DNA concentrations through inspection of samples electrophoresed on $1 \%$ agarose gels containing ethidium bromide.

\section{AFLP procedure}

Our AFLP methodology was essentially as described in Krauss (1999), with the following modifications. For each leaf sample, we digested and ligated approximately $200 \mathrm{ng}$ of genomic DNA using the AFLP Core Reagent Kit (Life Technologies). We added $1.4 \mu \mathrm{l}$ of a $1 \mathrm{mg} / \mathrm{ml}$ solution of RNAse in each $25 \mu \mathrm{l}$ restriction digest reaction to remove the large amount of RNA present in G. caleyi DNA extracts. We confirmed complete digestion of genomic DNA by visualisation on an agarose gel. We carried out all PCR reactions in $0.2 \mu \mathrm{l}$ PCR tubes using a PTC-100 thermal cycler (MJ Research). The touchdown reaction for selective PCR amplification commenced with one cycle of $94^{\circ} \mathrm{C}$ for $30 \mathrm{~s}, 65^{\circ} \mathrm{C}$ for $30 \mathrm{~s}$ and $72^{\circ} \mathrm{C}$ for $60 \mathrm{~s}$, followed by reduction of the annealing temperature in each cycle by $1^{\circ} \mathrm{C}$ from 65 to $56^{\circ} \mathrm{C}$. We maintained the annealing temperature at $56^{\circ} \mathrm{C}$ for 23 cycles.

We combined denatured PCR products with loading mix containing GeneScan Rox 500 internal size standard (Applied Biosystems), and visualised these on 5\% polyacrylamide gels containing $8 \mathrm{M}$ urea, on an $\mathrm{ABI}$ Prism 377 automated DNA sequencer. We then determined fragment sizes from multilocus profiles using $\mathrm{ABI}$ Prism GeneScan Analysis software (PE Applied Biosystems, Version 3.1). We scored each AFLP profile for the presence (1) or absence (0) of fragments using ABI Prism Genotyper software (Perkin-Elmer, Version 1.1.1). If fragments were poorly amplified across a profile, we repeated the selective amplification.

We screened nine primer pairs for variation using at least two plants from each of five populations. We then selected the three most informative of these primer pairs, $\mathrm{M}-\mathrm{CAT} / \mathrm{E}-\mathrm{ACT}, \mathrm{M}-\mathrm{CAT} / \mathrm{E}-\mathrm{AAC}$ and M-CAC/E-ACT, for use in this study. We multiplexed the two reactions sharing a common MseI primer in the same selective PCR reaction, and assayed all G. caleyi plants for each of the three primer pairs.

\section{Data analysis}

We constructed a $0 / 1$ data matrix comprising all individuals and all polymorphic fragments. We considered a fragment polymorphic if it was absent in at least one individual. To ensure repeatability we omitted any fragments with peak intensities that were inconsistent across individuals, or consistently yielded low-intensity bands. In addition, we removed eight sampled individuals from the analysis because repeated attempts failed to produce satisfactory fragment amplification, reducing sample sizes to eight or nine in most populations (Table 1). In performing the statistical analyses, we assumed that each variable locus had two allelic states: the first producing the observed fragment and resulting from either a homozygote or heterozygote containing the single dominant allele, and the second indicated by the absence of the fragment and resulting from the absence of the dominant allele.

We calculated within-population genetic diversity over all loci taken singly as the per cent polymorphic loci $(P)$ and Shannon's information index $\left(H_{\mathrm{s}}\right)$ using POPGENE Version 1.32 (Yeh et al, 1997). We also tallied the number of unique fragments (a measure of the number of 'private alleles') possessed by each population, but did not estimate heterozygosity because when dealing with dominant markers such as AFLPs, the calculation requires that populations are in Hardy-Weinberg equilibrium. This assumption is unlikely to be met in G. caleyi, given its capacity for selfing and lack of seed dispersal.

To describe the patterns of genetic differentiation within and among ridges we constructed genetic distance matrices for the three sets of primer pairs separately and for the combined data with the program GenAlEx V5 (Peakall and Smouse, 2001), using the Euclidean distance metric of Excoffier et al (1992) and Huff et al (1993), which deals with all loci simultaneously. We determined the relationships between the three primer-specific genetic distance matrices, and the significance of the correlations, using Mantel tests performed in ARLEQUIN Version 2.000 (Schneider et al, 2000) with 10000 permutations. We used ARLEQUIN to 
Table 1 Details of the eight populations of Grevillea caleyi used in this study

\begin{tabular}{|c|c|c|c|c|c|c|c|c|}
\hline Ridge & Pop. & Pop. age (last fire) & Pop. size & $\mathrm{N}$ & No. unique phenotypes & No. unique alleles & $\mathrm{P}(S E)$ & $\mathrm{H}_{s}(S E)$ \\
\hline 1 & DF & 10-13 (?) & $\sim 500$ & 10 & 5 & 2 & 12.82 & $0.059(0.051)$ \\
\hline 1 & NR & 9-12 (?) & 80 & 8 & 8 & 0 & 41.03 & $0.198(0.089)$ \\
\hline 2 & LR & $2(3)$ & 14 & 9 & 9 & 0 & 41.03 & $0.229(0.098)$ \\
\hline 2 & MR & $4(3-6)$ & 9 & 9 & 8 & 0 & 33.33 & $0.185(0.093)$ \\
\hline 2 & RT & $4(15)$ & $\sim 1500$ & 10 & 9 & 0 & 30.77 & $0.169(0.085)$ \\
\hline 3 & FW & $>13(?)$ & 60 & 9 & 9 & 1 & 33.33 & $0.190(0.093)$ \\
\hline 3 & $\mathrm{BQ}$ & 3.5 (15) & $\sim 1000$ & 8 & 8 & 1 & 38.46 & $0.225(0.106)$ \\
\hline \multirow[t]{3}{*}{4} & BT & $4(14-19)$ & $\sim 2000$ & 8 & 8 & 1 & 38.46 & $0.211(0.100)$ \\
\hline & Total & - & - & 71 & 64 & 5 & - & - \\
\hline & Mean & - & - & - & - & - & $33.65(3.27)$ & $0.183(0.019)$ \\
\hline
\end{tabular}

Presented are ridge location, estimated population age at the time of sampling (and at the time of the last fire, shown in parentheses if known, ? if not known), approximate population size, sample size $(N)$, number of unique AFLP phenotypes, number of unique alleles, per cent polymorphic loci $(P)$, and Shannon's information index $\left(H_{s}\right)$. Standard errors are shown in parentheses.

partition genetic variation among individuals within populations, among populations within ridges and among ridges in an analysis of molecular variance (AMOVA).

We also generated genetic similarity matrices for the combined data set using the Jaccard similarity coefficient, $\mathrm{GS}_{i j}=a /(a+b+c)$, where $\mathrm{GS}_{i j}$ is the measure of genetic similarity between individuals $i$ and $j, a$ is the number of bands shared by $i$ and $j, b$ is the number of bands present in $i$ but absent in $j$ and $c$ is the number of bands present in $j$ but absent in $i$. We then used nonmetric multidimensional scaling (MDS) in three dimensions to provide a visual representation of the genetic relationships among plants.

We used POPGENE to calculate Nei's (1978) genetic distance, which is based on means over loci, among all populations from the $0 / 1$ data matrix. To test for a correlation between Nei's (1978) genetic distance and geographic distance among populations, we used ARLEQUIN to perform a Mantel test with 10000 permutations. We then determined the relationship between log (population size) and genetic diversity (estimated as per cent polymorphic loci and Shannon's index), using Pearson's product moment correlation coefficient. This was repeated for $\log$ (population isolation), where isolation was measured as the distance to the nearest extant population.

\section{Results}

\section{AFLP markers}

Using three primer pairs, we generated 127 DNA fragments between 88 and 420 bp (Table 2). Of these, 56 $(44.1 \%)$ were polymorphic across $71 \mathrm{G}$. caleyi individuals from eight populations, but only 39 fragments were consistently scorable. We detected at least moderate amounts of genetic diversity within all sampled populations. The percentage of polymorphic loci varied from $12.82 \%$ at DF to $41.03 \%$ at LR and NR, with a population average of $33.65 \%$ (Table 1). Shannon's information index ranged from 0.059 at DF to 0.229 at LR, with a population average of 0.183 (Table 1). Per cent polymorphic loci and Shannon's index were highly and significantly correlated ( $\left.r_{P}=0.973, P<0.001\right)$.

A total of $90 \%$ of the $71 \mathrm{G}$. caleyi individuals had unique AFLP phenotypes (Table 1). Most of the shared
Table 2 Summary details of the AFLP fragments generated from three primer combinations in 71 individuals of G. caleyi from eight populations ( $8.9 \pm 0.3$ plants were sampled per population)

\begin{tabular}{lcccc}
\hline Primer pair & $\begin{array}{c}\text { No. of } \\
\text { fragments }\end{array}$ & $\begin{array}{c}\text { No. of } \\
\text { polymorphic } \\
\text { fragments }\end{array}$ & $\begin{array}{c}\text { Per cent } \\
\text { polymorphism }\end{array}$ & $\begin{array}{c}\text { No. of } \\
\text { polymorphic } \\
\text { fragments } \\
\text { scored }\end{array}$ \\
\hline M-CAT/E-ACT & 42 & 15 & 35.7 & 9 \\
M-CAT/E-AAC & 48 & 21 & 43.7 & 13 \\
M-CAC/E-ACT & 37 & 20 & 54.0 & 17 \\
Total & 127 & 56 & 44.1 & 39 \\
\hline
\end{tabular}

phenotypes occurred at DF; only one individual from this population displayed a unique phenotype, and the remaining nine individuals each displayed one of thee four phenotypes. In contrast, all but two individuals at RT and MR had unique phenotypes, and no identical individuals were found in the other five populations. The genetic distance matrices generated from the three individual sets of primer pairs were significantly correlated with each other $\left(r_{\mathrm{m}}=0.392,0.437\right.$ and 0.473 ; $P<0.001$ in every case). However, the correlations were moderate rather than high and consequently each primer pair differed with respect to its ability to distinguish among particular individuals or groups.

\section{Population differentiation}

We found a very large degree of differentiation among G. caleyi populations. AMOVA revealed that $65.9 \%$ of the total genetic variation was among populations, and only $34.1 \%$ occurred among individuals within populations (Table 3 ). In addition, the three-dimensional MDS plot showed that nearly all individuals clustered in discrete population groups with very little overlap among populations (Figure 2). Unique AFLP fragments were found in four populations, with two unique fragments at DF and one at each of FW, BQ and BT (Table 1). Although the frequency of occurrence of the unique fragments within their respective populations ranged from 22 to $50 \%$, their detection may, to some extent, reflect the small number of individuals sampled from each population. 
Table 3 Analysis of molecular variance (AMOVA) for 71 G. caleyi individuals from eight populations within four ridges, using 39 AFLP markers

\begin{tabular}{lrrrr}
\hline Source of variation & $d f$ & SS & Variance component & P of total variance \\
\hline Among ridges & 3 & 165.21 & 1.09 & 14.23 \\
Among populations within ridges & 4 & 152.25 & 3.94 & 51.65 \\
Among individuals within populations & 63 & 163.98 & 2.60 & $<0.001$ \\
\hline
\end{tabular}

$P$-values indicate the probability of obtaining a more extreme variance component estimate by chance.

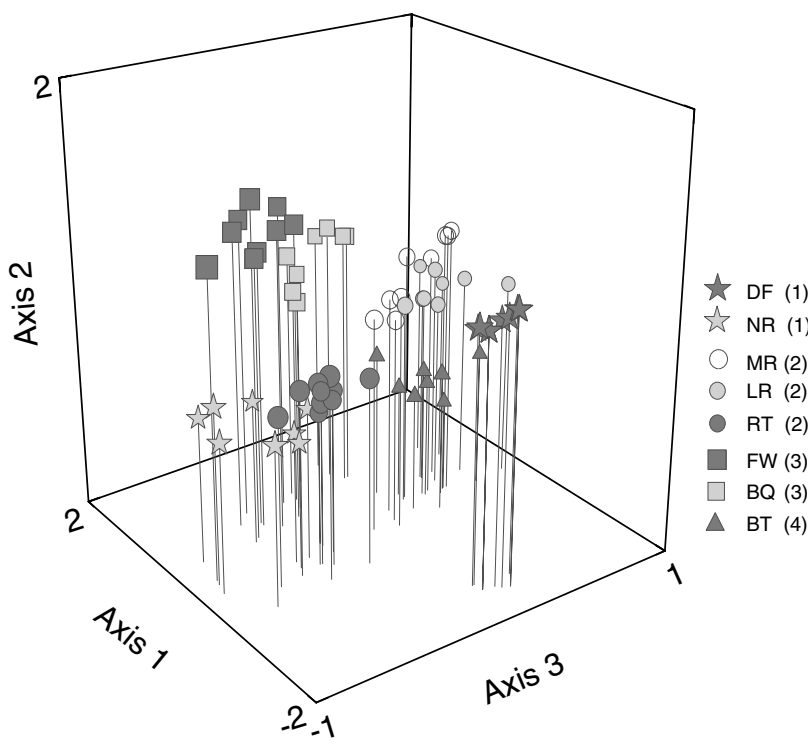

Figure 2 Three-dimensional plot of the nonmetric MDS analysis of a Jaccard similarity coefficient matrix calculated from 39 AFLP fragments, for $71 \mathrm{G}$. caleyi individuals. Individuals were sampled from eight populations on four ridges (ridge numbers shown in parentheses). Stress $=0.116$

There was a moderately strong and significantly positive relationship between geographic and genetic distance (Figure 3; $r_{\mathrm{m}}=0.564, P=0.004$ ).

Surprisingly, AMOVA revealed that far more genetic differentiation was present in population comparisons within $(51.65 \%)$ rather than among ridges $(14.23 \%)$ (Table 3). Examination of the MDS plot (Figure 2) revealed that two populations, DF (Ridge 1) and RT (Ridge 2), made the greatest contribution to this result. The genetic relationships between these and nearby populations were not consistent with their geographic relationships. RT showed more similarity to the relatively distant NR (Ridge 1) than to the other Ridge 2 populations (MR, LR), and DF was different to all other populations, particularly its ridge partner NR (Figure 2). However, when we recalculated the AMOVA with the assumption that DF and NR occur on separate ridges, we still found that the majority of variation occurred among populations within ridges $(43.85 \%)$, while only $22.27 \%$ of variation occurred among ridges. Nevertheless, several populations did show close genetic relationships with their geographic neighbours. The two Ridge 3 populations (FW and BQ) clustered closely together in their own group on the MDS plot, as did the remaining Ridge 2 populations (MR and LR). The sole population from Ridge 4, BT, formed a distinct group in the MDS that was most similar to its two geographically closest popula-

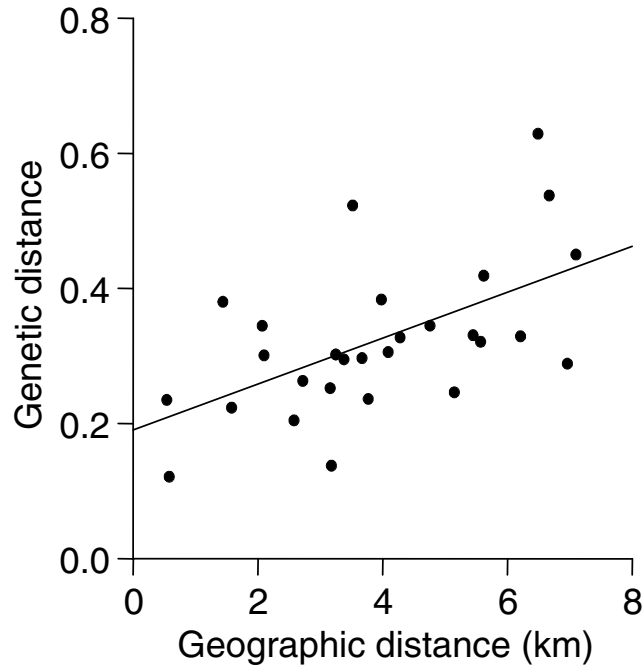

Figure 3 Relationship between genetic differentiation (measured as Nei's (1978) genetic distance) and geographic distance among eight G. caleyi populations, showing the linear regression. The correlation was tested with a Mantel test $\left(r_{\mathrm{m}}=0.564, P=0.004\right)$.

tions (LR and MR). The remaining population from Ridge 1, NR, differed substantially from the populations on other ridges (with the exception of RT).

\section{Effects of population size and isolation}

Despite the clear subdivision of the G. caleyi populations, we found no evidence for an overall effect of either population size or population isolation on genetic diversity. There was no relationship between log (population size) and either per cent polymorphic loci $\left(r_{P}=-0.226, P=0.590\right)$ or Shannon's index $\left(r_{P}=-0.199\right.$, $P=0.636$ ) (Figure 4 ). The slightly negative correlations were due to one relatively large population (DF) that contained comparatively very little genetic diversity (see the outlying pair of points in Figure 4). When this population was removed from the analysis, the above correlations became even weaker $\left(r_{P}=0.111, P=0.813\right.$; $r_{P}=0.041, P=0.931$, respectively). There was no relationship between $\log$ (population isolation) and per cent polymorphic loci $\left(r_{P}=-0.115, P=0.786\right)$ or Shannon's index $\left(r_{P}=-0.240, P=0.566\right)$.

\section{Discussion}

The magnitude and pattern of genetic subdivision that we found among populations of G. caleyi provides compelling evidence that there were ancient barriers to 


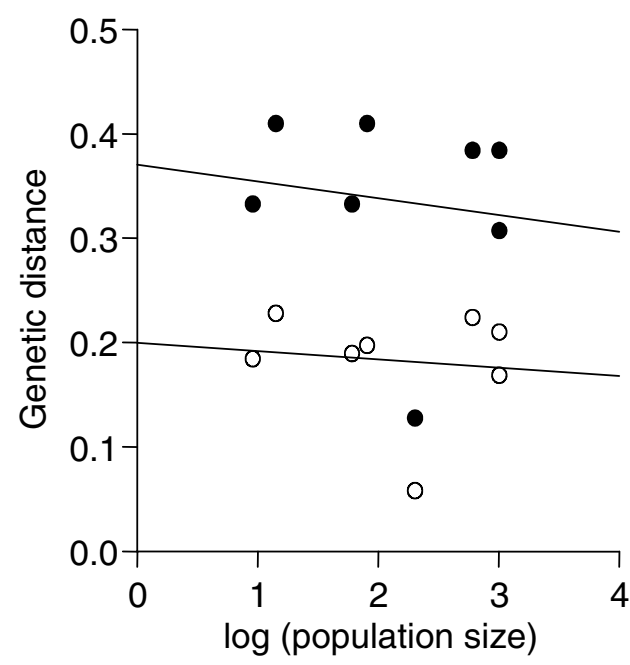

Figure 4 Relationship between log (population size) and genetic diversity, measured from AFLP data as the proportion of polymorphic loci (solid symbols) and Shannon's index (open symbols), for eight populations of G. caleyi. Linear regression lines are shown $\left(r_{P}=-0.226, P=0.590 ;\right.$ and $r_{P}=-0.199, P=0.636$, respectively).

gene flow among nearby ridges, and that recent fragmentation events have yet to impact genetically upon the remaining populations. Although we found genetic differentiation among all recently fragmented populations at a local level, that is, within ridges, it is likely that this differentiation resulted from pre-existing fine-scale genetic structuring within the prefragmented populations. The historical existence of extensive genetic structuring both within and between populations supports the predictions for an endemic species with a mixed mating system, limited pollen movement, very limited seed dispersal and spatial patchiness within populations (Loveless and Hamrick, 1984).

\section{Genetic structure within G. caleyi}

The most striking result of this study was the extremely large degree of genetic subdivision among the populations of $G$. caleyi. The average $G_{\mathrm{ST}}$ (from allozyme studies) for plants with a mixed mating system and gravity-dispersed seed is 0.248 (Hamrick and Godt, 1996). Therefore, the value we obtained for G. caleyi (65.9\% of variation among populations, equivalent to a $G_{S T}$ of 0.659 ) is exceptionally high with respect to both its mating system and method of seed dispersal, and more closely approximates the average $G_{\mathrm{ST}}$ for selfing species (0.533: Hamrick and Godt, 1996). Our result is even more significant when we consider the relatively small geographic distances separating populations. While many fragmented and/or endangered plant species with mixed mating systems have shown very high levels of interpopulation genetic differentiation (eg, Starr and Carthew, 1998; Coates and Hamley, 1999; Gaudeul et al, 2000), almost invariably the studied populations were separated by much larger geographic distances than the G. caleyi populations. The closely related G. macleayana, which is distributed over a slightly larger area than G. caleyi but has a similar mating system, pollination syndrome and lack of seed dispersal, had a much lower level of population differentiation $\left(F_{\mathrm{ST}}=0.218\right.$ : England et al, 2002), as did the outcrossing but geographically very restricted G. iaspicula $\left(F_{\mathrm{ST}}=0.204\right.$ : Hoebee and Young, 2001).

The patterns of genetic divergence that we detected among populations of G. caleyi generally fit the pattern expected for isolation by distance. There were large genetic differences between populations from different ridges, with the exception of a single pair of populations. This result supports our prediction that ridges should show large genetic differences due to historical isolation, and suggests the long-term action of genetic drift, founder events and inbreeding within ridge-based populations or subpopulations, with limited gene flow among them. It is reasonable to assume the occasional transfer of pollen among ridges, thus maintaining limited genetic connection among the ridges. This is supported by the absence of unique AFLP fragments in populations from the centrally located Ridge 2, which is the least isolated from other ridges and probably receives the largest amount of inter-ridge gene flow; in contrast, the three peripheral ridges each contained unique AFLP fragments.

We predicted that populations of G. caleyi within ridges might be genetically differentiated if aspects of the species' mating system, pollination biology and seed biology had created fine-scale genetic structuring within prefragmentation populations. This does appear to be the case, as both the AMOVA and MDS revealed substantial structuring within ridges. The available evidence suggests that this within-ridge structuring probably pre-dates European settlement; if such marked differentiation had resulted from recent genetic bottlenecks and changes in gene flow or the mating system, we should have also been able to detect a substantial decline in genetic polymorphism with current population size, and that was not the case.

Fine-scale structuring within G. caleyi populations may have three main causes. First, there is no apparent mechanism for dispersal of seeds away from the maternal plant (Auld and Denham, 1999), each patch of G. caleyi plants probably consists of closely related individuals. Second, genetic identity of individuals within patches would be further strengthened by selfing, which the mating system allows for ( $\mathrm{T}$ Llorens unpublished data). Third, pollinators may forage more within patches of plants than between them.

\section{Within-population genetic diversity}

Contrary to our expectations, we found little variation among G. caleyi populations with respect to either the percentage of loci that were polymorphic or the levels of genetic diversity assessed by Shannon's index. The clear exception was the DF population. Genetic diversity did not vary with either current population size or isolation, in contrast to many other studies (eg, Prober and Brown, 1994; Buza et al, 2000; Young et al, 2000). The numbers of plants in the smallest $G$. caleyi populations were so low (nine and 14 plants, respectively), and appear to have been low for several decades, that it is reasonable to expect some loss of genetic diversity in these populations. However, the absence of such a decline supports similar findings for populations of some long-lived species that have suffered recent fragmentation (eg, the endangered G. iaspicula; Hoebee and Young, 2001). 
Our finding that there are similar levels of genetic polymorphism in almost all extant populations of $G$. caleyi regardless of their size or degree of isolation should not, of course, be taken as evidence that the current fragmentation will have no genetic effects on this species. Rather than suggesting that fragments are in a mutation-drift balance, our results highlight the confounding effects that extended generation lengths (within life histories that include a dormant phase) may have on the rate of change of allele frequencies following fragmentation, and also the need to quantify pre-existing population subdivision. The most likely explanations for the maintenance of diversity in the smaller G. caleyi populations are that there may have been insufficient generations since initial habitat fragmentation to allow the loss of diversity, and that both the effective population size and generation length are strongly influenced by the soil seed bank.

Genetic drift depends on the number of generations for which a population remains small (Barrett and Kohn, 1991). Little information is available on how many generations have passed since each of the G. caleyi populations was fragmented. Generation times in obligate-seeder plant species depend on fire frequency, and interfire periods for $G$. caleyi may have ranged from a few years to as many 20 or 30 years (Scott et al, 1995).

A considerable proportion of the real abundance of G. caleyi at a site may be found in the seed bank and a census of above-ground plants will significantly underestimate actual population size. The genetic diversity contained in the seed bank of a small population may be sufficient to buffer the loss of diversity from several subsequent adult generations following even severe reductions in population size (Levin, 1990). Few studies have investigated this possibility, but evidence supporting it is growing (eg, McCue and Holtsford, 1998; Morris et al, 2002). It is important to note that this buffering of genetic drift in a small population can only be temporary, and will not be a long-term solution to the maintenance of diversity. Indeed, the rate of depletion of genetic diversity from the seed bank is likely to accelerate in the future due to increased fire frequency, as this urban bushland area now regularly experiences hazard reduction burns and deliberately lit wildfires. A series of short interfire intervals would prevent the accumulation of a soil seedbank (Regan et al, 2003), thus dramatically reducing population size and rendering it much more vulnerable to the loss of genetic diversity through drift and increased inbreeding. Some evidence suggests that the sizes of several G. caleyi populations are decreasing with sequential fires ( $\mathrm{T}$ Auld, personal communication).

The apparent historical isolation of one G. caleyi population may provide insights into some of the potential long-term genetic consequences of recent habitat fragmentation. It was somewhat surprising to note that DF, one of the larger populations, was the only one of the eight populations that displayed reduced genetic diversity; it possessed less than half the genetic diversity of any other population, and only five AFLP phenotypes were identified from among its 10 genotyped individuals. This suggests that one or more population bottlenecks have occurred at DF in the past, either through the initial founding of the population or during periods of small population size. The relative geographic isolation of DF (only one other population is currently located within $3.5 \mathrm{~km}$ of DF) appears to have prevented it from increasing its genetic diversity through gene flow and also allowed it to diverge genetically. The extreme genetic differentiation between DF and NR on Ridge 1, along with the very narrow constriction of the ridge between these populations, suggests that these two populations may not have been historically connected. Alternatively, it is possible that historically strong selective pressures favouring a limited array of highly adaptive genotypes could have been the cause of low genetic diversity at DF. This is unlikely, however, because there are no obvious differences between this and other populations in physical site characteristics or in plant morphology. This case illustrates both the apparent longterm genetic impact of natural fragmentation, and that events in a population's history can be far more important than current population size in determining genetic diversity.

\section{Acknowledgements}

Financial support was provided by an ARC grant to DJA and RJW, and the University of Wollongong's Institute for Conservation Biology. Additional financial and logistical support was provided by the New South Wales National Parks and Wildlife Service. We thank Rod Peakall for his assistance with the initial application of AFLP methodology for Grevillea. Tony Auld provided invaluable advice and discussion. We thank two anonymous referees for their comments on an earlier version of this paper. This is paper \# 244 from the Ecology and Genetics Group of the University of Wollongong.

\section{References}

Auld TD, Denham AJ (1999). The role of ants and mammals in dispersal and post-dispersal seed predation of the shrubs Grevillea (Proteaceae). Plant Ecol 144: 201-213.

Barrett SCH, Kohn JR (1991). Genetic and evolutionary consequences of small population size in plants: implications for conservation. In: Falk DA, Holsinger KE (eds) Genetics and Conservation of Rare Plants. Oxford University Press: New York, pp 3-30.

Buza L, Young A, Thrall P (2000). Genetic erosion, inbreeding and reduced fitness in fragmented populations of the endangered tetraploid pea Swainsona recta. Biol Conserv 93: $177-186$.

Coates DJ, Hamley VL (1999). Genetic divergence and the mating system in the endangered and geographically restricted species, Lambertia orbifolia Gardner (Proteaceae). Heredity 83: 418-427.

Doyle JJ, Doyle JL (1987). A rapid DNA isolation procedure for small quantities of fresh leaf tissue. Phytochem Bull 19: 11-15.

England PR, Usher AV, Whelan RJ, Ayre DJ (2002). Microsatellite diversity and genetic structure of fragmented populations of the rare, fire-dependent shrub Grevillea macleayana. Mol Ecol 11: 967-977.

Excoffier L, Smouse PE, Quattro JM (1992). Analysis of molecular variance inferred from metric distances among DNA haplotypes: application to human mitochondrial DNA restriction sites. Genetics 131: 479-491.

Foré SA, Hickey RJ, Vankat JL, Guttman SI, Schaefer RL (1992). Genetic structure after forest fragmentation: a landscape ecology perspective on Acer saccharum. Can J Bot 70: 16591668.

Frankham R, Ralls K (1998). Inbreeding leads to extinction. Nature 392: 441-442. 
Gaudeul M, Taberlet P, Till-Bottraud I (2000). Genetic diversity in an endangered alpine plant, Eryngium alpinum L. (Apiaceae), inferred from amplified fragment length polymorphism markers. Mol Ecol 9: 1625-1637.

Gibbs JP (2001). Demography versus habitat fragmentation as determinants of genetic variation in wild populations. Biol Conserv 100: 15-20.

Hamrick JL, Godt MJW (1996). Effects of life history traits on genetic diversity in plant species. Phil Trans $R$ Soc Lond B 351 1291-1298.

Hoebee SE, Young AG (2001). Low neighbourhood size and high interpopulation differentiation in the endangered shrub Grevillea iaspicula McGill (Proteaceae). Heredity 86: 489-496.

Huff DR, Peakall R, Smouse PE (1993). RAPD variation within and among natural populations of outcrossing buffalograss (Buchloë dactyloides (Nutt.) Engelm.)]. Theor Appl Genet 86: 927-934.

Husband BC, Schemske DW (1996). Evolution of the magnitude and timing of inbreeding depression in plants. Evolution 50: 54-70.

Krauss SL (1999). Complete exclusion of nonsives in an analysis of paternity in a natural plant population using amplified fragment length polymorphism (AFLP). Mol Ecol 8: 217-226.

Levin DA (1990). The seed bank as a source of genetic novelty in plants. Am Nat 135: 563-572.

Loveless MD, Hamrick JL (1984). Ecological determinants of genetic structure in plant populations. Ann Rev Ecol Syst 15: 65-95.

McCue KA, Holtsford TP (1998). Seed bank influences on genetic diversity in the rare annual Clarkia springvillensis (Onagraceae). Am J Bot 85: 30-36.

Montgomery ME, Woodworth LM, Nurthen RK, Gilligan DM, Briscoe DA, Frankham R (2000). Relationships between population size and loss of genetic diversity: comparison of experimental results and theoretical predictions. Conserv Genet 1: 33-43.

Morris AB, Baucom RS, Cruzan MB (2002). Stratified analysis of the soil seed bank in the cedar glade endemic Astragalus bibullatus: evidence for historical changes in genetic structure. Am J Bot 89: 20-36.

Nei M (1978). Estimation of average heterozygosity and genetic distances from a small number of individuals. Genetics 89: 583-590.

Newman D, Pilson D (1997). Increased probability of extinction due to decreased effective population size: experimental populations of Clarkia pulchella. Evolution 51: 354-362.
Oostermeijer JGB, van Eijck MW, van Leeuwen NC, den Nijs JCM (1995). Analysis of the relationship between allozyme heterozygosity and fitness in the rare Gentiana pneumonanthe L. I Evol Biol 8: 739-759.

Peakall R, Smouse PE (2001). GenAlEx V5: Genetic Analysis in Excel. Population Genetic Software for Teaching and Research. Australian National University: Canberra, Australia, http:/ / www.anu.edu.au/BoZo/GenAlEx/.

Prober SM, Brown AHD (1994). Conservation of the grassy white box woodlands: population genetics and fragmentation of Eucalyptus albens. Conserv Biol 8: 1003-1013.

Regan HM, Auld TD, Keith DA, Burgman MA (2003). The effects of fire and predators on the long-term persistence of an endangered shrub, Grevillea caleyi. Biol Conserv 109: 73-83.

Schneider S, Roessli D, Excoffier L (2000). Arlequin ver. 2.000: A Software for Population Genetics Data Analysis. Genetics and Biometry Laboratory: University of Geneva, Switzerland.

Scott J, Marshall A, Auld TD (1995). Conservation Research Statement and Recovery Plan for Grevillea Caleyi R.Br.. Endangered Species Project No. 456, Endangered Species Program, Australian Nature Conservation Agency.

Starr GJ, Carthew SM (1998). Genetic differentiation in isolated populations of Hakea carinata (Proteaceae). Aust J Bot 46: 671-682.

Turner ME, Stephens JC, Anderson WW (1982). Homozygosity and patch structure in plant populations as a result of nearest-neighbor pollination. Proc Nat Acad Sci USA 79: 203-207.

Wright S (1969). Evolution and the Genetics of Populations, Vol. 2: The Theory of Gene Frequencies. University of Chicago Press: Chicago.

Yeh FC, Yang R-C, Boyle T (1997). POPGENE, version 1.32. University of Alberta and CIFOR.

Young A, Boyle T, Brown T (1996). The population genetic consequences of habitat fragmentation for plants. Trends Ecol Evol 11: 413-418.

Young AG, Brown AHD, Murray BG, Thrall PH, Miller $\mathrm{CH}$ (2000). Genetic erosion, restricted mating and reduced viability in fragmented populations of the endangered grassland herb Rutidosis leptorrhynchoides. In: Young AG, Clarke GM (eds) Genetics, Demography and Viability of Fragmented Populations. Cambridge University Press: Cambridge, pp 335-359. 